\title{
AS HISTÓRIAS EM QUADRINHOS NA FORMAÇÃO DO LEITOR
}

\author{
Ada Aparecida Alves de Arruda ${ }^{1}$ \\ Elidiane Benedita da Silva ${ }^{2}$ \\ Hingridy Karoliny de Queiroz Arruda ${ }^{3}$ \\ Jaqueline de Moura Santana ${ }^{4}$ \\ Luciana Xavier Cirino ${ }^{5}$ \\ Sofia Ambrosa Alves Costa ${ }^{6}$
}

RESUMO: Este artigo teve como objetivo compreender a importância das Histórias em Quadrinhos (HQ) para a formação de leitores. A sua realização foi motivada pelas observações em nossas práticas pedagógicas, quando percebemos a grande dificuldade que os alunos têm na leitura, portanto, pretende-se colaborar com os futuros educadores e profissionais, para que possam melhorar suas salas, torná-las divertidas e especiais, oferecer aos alunos aulas entusiasmadas, por meio da inclusão dos quadrinhos como forma de aprendizado.

Palavras-chave: Histórias em Quadrinhos. Leitura e Aprendizagem.

ABSTRACT: This article aimed to understand the importance of Comics (Comic) for the formation of readers. Its achievement was motivated by observations in our pedagogical practices, when we realized the great difficulty that students have in reading. With this article, therefore, it is intended to collaborate with future educators and professionals, so that they can improve their classrooms, make them fun and special, offer enthusiastic classes to students, through the inclusion of comics as a way of learning.

Key-words: Comic Stories. reading and learning.

\section{INTRODUÇÃO}

Para Vergueiro (2004), desde o surgimento da humanidade, a escrita e os desenhos são elo de comunicação entre as pessoas, quer seja através de um recado desenhado nas paredes das cavernas, nas quais viviam o homem primitivo, quer seja pelo

\footnotetext{
I Graduada em Pedagogia pela FIAVEC - Faculdades Integradas de Várzea Grande, Especialista em Educação Infantil com Ênfase no Letramento pelas Faculdades Integradas de Cuiabá - FIC.

${ }^{2}$ Graduada em Pedagogia pela UNIC - Universidade de Cuiabá, Especialista em Neuroeducação pela FEICS

- Faculdade Evangélicas Integradas Cantares de Salomão.

${ }^{3}$ Graduada em Pedagogia pela Universidade Norte do Paraná - UNOPAR, Especialista em Educação pela Faculdade Afirmativo.

${ }^{4}$ Graduada em Pedagogia pela Universidade Norte do Paraná - UNOPAR.

${ }_{6}^{5}$ Formação Ensino Técnico Magistério pelo Instituto de Educação Carlos Pasquale.

6 Graduada em Pedagogia pela UFMT - Universidade Federal de Mato Grosso, Especialista em Atendimento Educacional Especializado pela Faculdade de Educação de Taganrá da Serra.
} 
desenho de uma experiência relacionada ao seu cotidiano. Essas situações de escrita e de desenhos compõem o modo de comunicar, através de imagens gráficas, as quais apenas após estudos foram consideradas como tentativas de se falar, comentar os acontecimentos que aconteceram durante o dia das pessoas. Nesse período primitivo, a comunicação visual, um canal de informações próprio para o desenvolvimento da interação entre os seres humanos.

Este artigo, portanto se propõe estudar a importância das Histórias em Quadrinhos (HQ) para a formação do leitor. O mesmo objetiva despertar o interesse pela importância das HQ para a formação de leitores, bem como para que os educadores possam utilizar as $\mathrm{HQ}$, como recurso na aprendizagem. Para sua realização, foi utilizada a pesquisa bibliográfica.

O aumento do número de leitores das histórias em quadrinhos (HQ), proporcionou um canal de comunicação viável para as histórias em quadrinhos, além de altamente lucrativo para os empresários do ramo (VERGUEIRO, 2004).

Os Estados Unidos foi o local adequado para o desenvolvimento das $H Q$ devido a todas as vantagens, sejam as tecnológicas, sejam as de amparo econômico e social 1250 para a consagração total que existe em torno das histórias em quadrinhos nesse país.

No início, as publicações das histórias em quadrinhos surgiram voltadas para o estilo cômico, abordando a sátira e a caricatura, destinada a um público-alvo: os migrantes, sendo veiculadas de preferencial aos domingos nos jornais norte-americanos. Com o passar do tempo, a publicação que era de apenas uma vez por semana, tornou-se diária. As tiras eram uma maneira diferente e divertida de se lerem as histórias em quadrinhos (VERGUEIRO, 2004).

De uma temática cômica, existiu uma variação nos temas. É importante ressaltar que as HQ tinham um conteúdo repleto de mensagens americanizadas, nas quais se notava a veemente glorificação norte-americana e a valorização dos costumes e sua cultura. Observa-se a questão da ideologia, fortemente arraigada nas HQ e vendida pelo mundo afora numa maneira de se mostrar o poderio do país mais rico do planeta.

Após as tiras de quadrinhos, surgiram histórias de aventuras e depois os comics books, surgidos nos Estados Unidos, em 1920, marcando um novo período das histórias em quadrinhos e inaugurando uma nova visão das HQ. Lançando uma febre 
mundial, tal o significado e a importância, as HQ conquistaram milhões de fãs, eis então os super-heróis, os quais se tornaram a "coqueluche" da juventude.

A Segunda Guerra Mundial colaborou para a disseminar as HQe inclusive nas vendagens estratosféricas das histórias em quadrinhos.

\section{DESENVOLVIMENTO}

\section{I AS HISTÓRIAS EM QUADRINHOS}

Conforme Coelho (199I) a literatura infantil teve destaque maior com os livros de Monteiro Lobato, a partir dos anos de 1920. O criador da boneca Emília foi um grande representante da literatura infantil. Os livros, as publicações e os demais escritos da época tratavam acerca dos temas adultos e com a chegada de Lobato, um nacionalista, ocorreu-se a ênfase na temática infantil, com histórias destinadas às crianças, transformando a literatura de uma vez por todas numa autêntica alternativa para as crianças e especialmente para os adultos, através de uma linguagem popular e criativa, conquistando leitores e leitoras assíduos.

Em 1920 emergiu Monteiro Lobato, a partir de 1930, no campo político existiu turbulência, tanto no Brasil com a "Era Vargas" e a Ditadura, quanto no exterior (Quebra da Bolsa de Valores de Nova York) resultando no aumento de escritos baseados em histórias infantis.

Para Coelho (199I) a preocupação dos escritores era a de alcançar as crianças com histórias engraçadas, favorecendo lazer a quem não tinha outro tipo de informação. Dessa forma, as histórias em quadrinhos tornaram-se necessárias, pois tinham uma maneira de comunicação fácil, dispostas em quadrinhos, assim colaborando para o aumento do número dos leitores.

Nos anos 5o, com o governo do presidente Juscelino Kubitschek, proferindo em seu discurso o lema " 50 anos em 5", no qual ficavam compreendidos todos os setores na rápida resolução de todos os problemas brasileiros, isto é, em apenas um mandato seriam solucionadas todas as mazelas sociais, inclusive as educacionais, o que ficou, infelizmente, na teoria. Em contrapartida, as produções em quadrinhos americanas adentram o país 
(Walt Disney) demonstrando que os popularmente conhecidos gibis, caíram no gosto do povo, fazendo-os “devorar” as publicações de HQ (COELHO, 1991).

As HQ trouxeram para si inúmeros leitores, crianças que procuravam essa forma de diversão. É importante mencionar as vantagens financeiras para autores e o sucesso cada vez mais estrondoso dos gibis, os quais atraiam a atenção de vários investidores.

As HQ de modo lento conseguiam ocupar posição de destaque na esquecida e desapoiada literatura brasileira, transformando-se numa opção diferente à literatura adulta, influenciada pelos quadrinhos americanos, cuja temática era amplamente seguida, seja no modo de se falar (gíria), de se vestir e até mesmo ideologicamente.

A década de 6o espelhava o advento da tecnologia, a chegada da televisão e de todo o magnetismo exercido pela mesma. A imagem gerada pela televisão ofuscada pelo marketing despejado nas casas das pessoas e influenciava o desvairado consumo de roupas, souvenirs, perfumes, automóveis, ou seja, realizando os sonhos de consumo de todo o mundo.

Naquele tempo, o que se via, era o descaso em relação às crianças, relegadas a uma literatura adulta e imprópria para sua idade. Após o esclarecimento inicial, é conveniente retomar a história do nascimento da revista $\mathrm{O}$ Tico-Tico, uma vez que foi a precursora do gênero infantil no Brasil, revolucionando, por ser a primeira revista de quadrinhos do Brasil, lançada em II de outubro de 1905, a qual veio a ser uma fonte de alegria para todas as pessoas, principalmente para a faixa etária infanto-juvenil e também se tornou um modelo a ser copiado e reproduzido, devido a sua proposta inovadora. Naquele tempo, o que se via, era o descaso em relação às crianças, relegadas a uma literatura adulta e imprópria para sua idade.

O Tico-Tico surgiu da necessidade de se ter uma publicação totalmente brasileira e apareceu pelas mãos de Luís Bartolomeu de Sousa e Silva, jornalista mineiro, o “pai” da primeira revista em quadrinhos do país. De acordo o informado, os Estados Unidos e a Europa já publicavam quadrinhos que mesmos circulavam por todo o planeta, inclusive pelas terras brasileiras, estampando histórias estrangeiras, as quais fascinavam os leitores. Essa paixão pelas HQ estimulou o jornalista brasileiro, à criação de um espaço, no 
qual seriam fornecidas a diversão e a informação por meio de uma revista em quadrinhos, algo inovador para a sociedade da época.

\subsection{HISTÓRIAS EM QUADRINHOS - HQ}

Como toda inovação, as HQ na época foram vistas com desconfiança por parte dos educadores, talvez pelo medo do poder inserido nas histórias, muitas vezes aparentemente ingênuas, que consistiam em perigosos influenciadores, sobretudo no modo de ser e de agir das pessoas. Dessa formas as HQ estrangeiras deixavam os governantes preocupados com a implantação de idéias revolucionárias nas mentes dos jovens, os quais poderiam ser desvirtuados de seu nacionalismo.

No entanto, as HQ apesar de provocarem várias divergências, tiveram sucesso em sua caminhada rumo a um tipo de linguagem reconhecidamente popular, pois o número de leitores crescia vertiginosamente, junto com as críticas, desfavoráveis às revistas em quadrinhos e todo o seu sucesso, o que resultava, em imensa quantidade de exemplares vendidos.

De modo gradual as HQ superaram os obstáculos do preconceito de serem desaconselháveis como material de estudo, de servirem apenas como forma de divertimento, isto é, como uma ludicidade para os jovens e crianças. Os críticos, impiedosos, viam os quadrinhos como prejudiciais para a juventude, podendo levar as crianças a se desinteressarem pelos estudos, o que não aconteceu, devido aos conteúdos educativo e moralista encontrados nas revistas.

É de conhecimento público a relevância das HQ em todo o mundo e do sucesso inerente às histórias, o que demonstra ser um meio de comunicação poderoso e influente. Apesar do advento da internet, de outros meios de comunicação, as HQ não param de conquistar fãs e nem de se sair do topo de vendagens de revistas. A questão de ser popular e da fácil acessibilidade são provas da enorme lucratividade das HQS. A indústria das revistas foi com o passar dos anos, sendo profissionalizada, resultando um sistema organizado e culminando num processo globalizado e capitalista.

A durabilidade do sucesso das HQ somente reforça o quanto as interferem na vida das pessoas, seja incutindo cultura, ideologia ou pensamentos. As revistas em quadrinhos auxiliam no processo de aprendizagem, pela abordagem lúdica de seus textos, 
contrariando boa parte de críticos, cuja "angústia" parte do fato de que as revistas em quadrinhos nada contribuem na formação escolar do aluno.

É verdade que as HQ geraram certo desconforto para muitos profissionais, inclusive da educação e para os pais dos alunos. Talvez seja pelo tremendo sucesso das revistas e do fascínio que exerciam (e exercem um carisma até hoje). É preciso explicar que as revistas em quadrinhos traziam uma bagagem lúdica, altamente explorada pela mídia e por ter essa característica de diversão sofreu um sério preconceito (VERGUEIRO, 2004).

O esclarecimento também se deve ao seguinte fato: as HQ são um veículo comercial muito rentável, o que contribuiu para ser considerada uma vilã em potencial, a qual poderia ser prejudicial aos jovens leitores. Os críticos eram muito desfavoráveis aos quadrinhos, tanto pelo seu apelo popular, tanto pelo grande consumo das revistas pelas crianças e pelos jovens. A contrariedade dos professores em relação aos quadrinhos somouse a dos pais das crianças (VERGUEIRO, 2004). Os professores não aceitavam esse veículo de comunicação, porque achavam que as HQS não possuíam conteúdo educativo para as crianças, ou seja, não contribuiriam em nada com a educação dos discentes.

As HQ tiveram que enfrentar muita resistência para sobressair e conseguir uma posição de destaque para o educador. No início, diversos professores deram as costas à entrada dos quadrinhos nas salas de aula, com o passar do tempo e após muita luta, as revistas em quadrinhos e suas histórias foram incluídas no planejamento dos educadores. Os livros didáticos também contam com atividades repletas de tiras de histórias em quadrinhos, até com textos inteiros, refletindo a tendência mundial da inclusão das HQ nas escolas, nas salas de aula (VERGUEIRO, 2004).

Em virtude desta inserção das HQ como ferramenta de apoio à aprendizagem, baseada nas histórias em quadrinhos, analisando livros didáticos e propondo-me a investigar como os livros didáticos utilizavam as HQem suas unidades.

Apenas cair no gosto popular não significava necessariamente agradar aos críticos, pois eles não achavam que as HQ possuíam cunho educativo, sendo meramente um veículo desinformativo e totalmente anti-intelectual (VERGUEIRO, 2004).

Os críticos julgavam de maneira impiedosa o conteúdo dos gibis e o acesso fácil pelo qual os admiradores adquirem as HQ. A crítica sustentava que as HQ não levariam conhecimento, por meio de textos didáticos e sim contribuíam negativamente 
para a deformação do intelecto das pessoas, principalmente das crianças - as mais ardorosas fãs deste gênero infantil.

\subsection{AS ESPECIFICIDADES DAS HISTÓRIAS EM QUADRINHOS}

As HQ são histórias narradas com desenhos em seqüência, geralmente no sentido horizontal, dispostos em tiras, apresentando diálogos dispostos em balões. A disposição dos balões dá uma idéia de rapidez e agilidade para as histórias e suas narrativas.

As HQ constituem-se numa fonte de diversão constante e barata para crianças e adolescentes, as quais contribuem para a construção dos futuros leitores, porque muitas vezes as crianças iniciam-se no mundo da leitura, por meio do conhecimento e leitura dos gibis (MARTINS, 2004). Por terem esta dinâmica e esta fácil acessibilidade, as HQ são consideradas um gênero textual, cuja relevância foi conquistada duramente e sofrendo inúmeras críticas, conforme explicitado anteriormente. As $H Q$ e porém firmaram-se e solidificaram seu sucesso, conseguindo para si fãs por todos os países (MARTINS, 2004).

As histórias em quadrinhos influenciam pela comunicabilidade, por serem dispostas em tiras, transformando-se num meio rápido de informações, num mundo globalizado e exigente de notícias e entretenimento.

As histórias em quadrinhos são elaboradas de forma a entreter, têm figuras, são alegres e coloridas, com isso distraem os leitores, cuja sensação de divertimento pode ser percebida pela leitura das tiras, as quais de curta durabilidade e com histórias simples e com uma linguagem, verbal ou não. Por isso é muito importante a veiculação dos personagens, de seus vestuários, de seu linguajar, procurando agradar o leitor (MARTINS, 2004).

Este mesmo leitor cria expectativas sobre os personagens, acerca das histórias, sobre a conduta deles, durante as situações criadas, o que ocasiona na adoração do fã/leitor de histórias em quadrinhos.

Realmente as $\mathrm{HQ}$ atraem os leitores, principalmente os que estão adentrando pela primeira vez no mundo da leitura. As HQ contribuem muito para a 
formação inicial deste leitor, por serem estimulantes visualmente e por conterem histórias simples e que provocam a curiosidade e a imaginação da criança ou do adulto.

As HQ ajudam no processo de alfabetização, na diferenciação das linguagens regionais, evidenciando o linguajar culto do coloquial, auxiliam no processo cognitivo da criança, em suas habilidades, transformando-o num ser crítico, capaz de agir e criar histórias.

\section{CONCLUSÃO}

Neste artigo tratamos da importância dos quadrinhos para a formação dos leitores, por meio de um breve histórico das HQ a fim de compreender a evolução deste gênero literário. As HQ são importantes para formar o leitor, pois as histórias contam acontecimentos do cotidiano. As HQ estão prontamente disponíveis para qualquer pessoa, pois são um investimento barato e os textos curtos atraem um grande público.

As HQ são envolventes e, portanto, ajudam os leitores, na busca por outras formas de textos, ou seja, como este poderiam ingressar em outros gêneros, formando um público duradouro e estimulando o hábito da leitura, um hábito saudável e necessário. As HQ fazem muito pela formação do leitor, pois são visualmente estimulantes e contêm histórias simples que estimulam a curiosidade e a imaginação de crianças ou adultos.

O tema tratado neste artigo é muito interessante devido à importância dos quadrinhos como ferramenta educacional para futuros leitores, uma vez que desde uma perspectiva atual sabemos que muitas pessoas não estão acostumadas a ler.

\section{REFERÊNCIAS}

COELHO, Nelly Novaes. Panorama Histórico da Literatura Infantil/Juvenil. $4^{\underline{a}}$ ed. São Paulo: Ática, 1991.

MARTINS, Silvane Aparecida de Freitas. Histórias em Quadrinhos: Um convite Para a iniciação do leitor. In: I SIMPÓSIO CIENTÍfICO-CULTURAL, 2004. Anais. Paranaíba: UEMS, 2004.

VERGUEIRO, W. Uso das HQ no ensino In:__(Org), Como usar as histórias em quadrinhos na sala de aula.São Paulo: Contexto, 2004. 